\title{
To study and evaluate the efficacy of amniotic membrane graft with conformer compared with mucous membrane graft with conformer in mild to moderate contracted socket
}

\author{
Ram Kumar ${ }^{1}$, Suroma Joysmine Marndi ${ }^{2, *}$ \\ ${ }^{1}$ Professor and Head, ${ }^{2}$ Junior Resident, Dept. of Ophthalmology, B.R.D. Medical College, Gorakhpur, Uttar Pradesh, India \\ *Corresponding Author: \\ Email: joysmine1990@gmail.com
}

\begin{abstract}
Aim: To evaluates the efficacy of both amniotic membrane transplantation and mucous membrane graft with conformer in each group in fornix reconstruction in mild to moderate contracted socket.

Materials and Methods: This study included 20 patients (10-60years) with mild-moderated contracted socket, attending OPD, Department of Ophthalmology in tertiary care hospital.

Study Design: observational study for one year patients were randomly grouped as Group A include 10 patients who underwent fornix reconstruction with AMG with conformer and rest 10 patients in Group B who underwent MMG with conformer, these patients were followed up on post-operative 3rd month, 6th month and 9th to assess the pre-operative and post-operative central inferior fornix depth.

Results: 20 patients of contracted socket were included in this study and randomly 10 patients each were categorized into Group A and Group B.GROUP A: AMG with conformer- The mean pre-operative and post-operative central inferior fornix measured was $3.19 \pm 0.28 \mathrm{~mm}$ and $7.09 \pm 0.15 \mathrm{~mm}$ respectively. Complete success in post-operative $9^{\text {th }}$ month was in 8 cases $(80 \%)$ while 2 cases $(20 \%)$ had partial success. GROUP B: MMG with conformer- The mean pre-operative and post-operative central inferior fornix measured was $3.04 \pm 0.24 \mathrm{~mm}$ and $6.94 \pm 0.18 \mathrm{~mm}$ respectively. Complete success in post-operative $9^{\text {th }}$ month was in 7 cases $(70 \%)$ while 3 cases $(30 \%)$ had partial success. There were no graft rejections. p-value 0.0001 in each group which was statistically very significant.

Conclusion: AMG and MMG with a conformer is a simple and safe method for fornix reconstruction in mild to moderate contracted socket.
\end{abstract}

Keywords: Amniotic membrane graft, Fornix reconstruction, Mucous membrane graft, Prosthesis, Symblepharon.

\section{Introduction}

The disfigurement of eye socket and the inability of an ocular prosthesis to fit within the socket has distressing as well as detrimental effect on the patient's self-esteem, during psychosocial interaction and sometimes affects their career life. Thereby, an anophthalmic eye and contracted socket is a big deal issue for all ophthalmologists. With the increasing awareness among the patients, it has become important to provide satisfactory cosmetic appearance of the prosthetic eye after an unavoidable disfigurement of the eye either after trauma or surgery.

Several etiologies have been considered for development of contracted socket mainly seen in patients after chemical injury, ocular pemphigoid, radiation therapy after enucleation of malignant tumour, improper or not using of prosthetic eye for a long time and can also occur if infections like endopthalmitis and panohthalmitis causing scarring of the conjunctiva. ${ }^{1}$

Contracted socket has been typically referred to a socket with presence of deep scar formation associated with loss of orbital tissue fat and extensive loss of conjunctival surface area. Sometimes contracted socket may be caused due to shallow inferior fornix which has sufficiently loose conjunctiva which is not attached to the underlying tissue.
Characteristics of an Anophthalmic Socket: The characteristics of the ideal socket and eyelid on the anophthalmic eye is:-

Normal position of the eyelashes and there is no inward or outward positioning of eyelids.

Presence of deep fornices.

Inferior fornix \& cul-de-sae that can support the weight prosthesis.

Superior lid and supratarsal fold that produces the normal follow eyelid.

On application of adequate sized ocular prosthesis, the prosthesis stay centrally within the socket, has good motility with eye and has a complete closure of the upper eyelid.

In an anophthalmic eye there is change in metabolism and in blood circulatory dynamics within the orbit. Due to decreased metabolism there decreased blood circulation leading into the atrophy of the orbital tissue fat in the anophthalmic eye. Atrophy of orbital fat within and outside the muscle cone area also contributes to the degree of enophthalmos present. In an enucleated eye due to disturbance in the anatomy of orbit the support from the levator muscle is also lost and there is sagging of the orbital septa leading to development of some degree of ptosis. ${ }^{2}$ 
Table 1: Assessment of the socket.

\begin{tabular}{|l|c|c|}
\hline S. No. & $\begin{array}{c}\text { Assessment of } \\
\text { the socket }\end{array}$ & Descriptions \\
\hline 1 & Area of socket & Depth of all four fornices; main importance is given to inferior fornix \\
\hline 2 & Volume of socket & Superior sulcus deformity indicates loss of volume of the socket. \\
\hline 3 & Dry/Wet socket & $\begin{array}{c}\text { Dry socket indicates poor vascularity. } \\
\text { Wet socket- presence of discharge may suggest poor hygiene and no proper } \\
\text { care - if prosthesis is being used. }\end{array}$ \\
\hline 4 & Movement & Presence of muscle movement has a better survival of grafts in fornix \\
reconstruction.
\end{tabular}

Classification of contracted socket

Table 2: Gopal Krishna classification ${ }^{1}$

\begin{tabular}{|c|c|}
\hline Grades & Descriptions \\
\hline Grade 1 & $\begin{array}{c}\text { The socket is characterized by a shallow lower fornix or shelving of the lower fornix, } \\
\text { preventing retention of a prosthesis. }\end{array}$ \\
\hline Grade 2 & Loss of the upper and lower fornices \\
\hline Grade 3 & Loss of the upper, lower, medial, and lateral fornices \\
\hline Grade 4 & $\begin{array}{l}\text { Loss of all fornices and reduction in the vertical and horizontal dimension of the } \\
\text { palpebral aperture. }\end{array}$ \\
\hline Grade 5 & $\begin{array}{c}\text { There is recurrence of contraction of the socket after a previous socket reconstruction } \\
\text { surgery. }\end{array}$ \\
\hline
\end{tabular}

Another Classification of Contracted Socket:

Mild includes grade I and II where either inferior or superior fornix is involved.

Moderate includes grade III where both superior and inferior fornices are involved.

Severe comprises of cases in which all fornices are involved along with reduced of palpebral aperture opening.

Malignant contracted socket is the most severe variety of contracted socket resulting from extensive fibrosis due to severe trauma or multiple surgeries. ${ }^{3}$

Contracted Socket Reconstruction Surgery: The main purpose of socket reconstruction surgery to allow socket for adequate retention of prosthesis with a good motility to provide satisfactory cosmetic appearance to the patient. These includes surgeries that deepen the superior and inferior fornices with the help of substrate such as AMG, MMG, fascia lata and dermis fat graft and use of conformers or symblepharon ring to support the graft and prevent fibrosis.

Table 3: Surgical management of contracted socket

\begin{tabular}{|l|c|}
\hline S. No. & Techniques used are \\
\hline 1 & Mucous membrane graft \\
\hline 2 & Amniotic membrane graft \\
\hline 3 & Prosthesis modification \\
\hline 4 & Epidermal graft \\
\hline 5 & Dermis fat graft \\
\hline 6 & Artificial Socket Expanders \\
\hline 7 & Fornix forming suture \\
\hline
\end{tabular}

An approach to the surgical management of the contracted eye socket is made after patient's history and complete assessment of the socket. A clinical assessment helps in grading of the contracted socket which helps in deciding the exact type of surgical management required from the several techniques available.

For mild to moderate grade of contracted socket amniotic membrane transplant or mucous membrane graft can be employed. For severely contracted socket requires an extensive resectioning of the tissue thereby a split thickness skin graft is consider to be a better option. Ocular implant that is extruding or exposed in contracted socket can be treated with dermal-fat graft.

Studies have shown that Amniotic membrane (AM) has a successful results in fornix reconstruction after symblepharon lysis in conditions having fibrosis of the conjunctiva. ${ }^{4}$

\section{Aim}

To evaluates the efficacy of both amniotic membrane transplantation and mucous membrane graft with conformer in each group in fornix reconstruction in mild to moderate contracted socket.

\section{Materials and Methods}

The study was conducted on 20 eviscerated eyes with mild to moderate contracted socket of patients aged between 10 to 60 years. Randomly 10 each patients were categorized into Group A and Group B. 
Group A patients underwent fornix reconstruction with amniotic membrane graft with conformer and rest 10 patients were grouped as Group B who underwent mucous membrane graft obtained from the patient's lower lip with conformer for fornix reconstruction. Followed up on 3 month, $6^{\text {th }}$ month and $9^{\text {th }}$ month postoperatively.

Inclusion Criteria: Eyes that had obliterated one fornix only (grade I, II/mild) or both superior and inferior fornices (grade III/moderate) who were unable to retain the prosthesis were included in this study.

Exclusion Criteria: Sockets with extensive shortening of lateral fornix or of all the four fornices, decreased palpebral aperture (severely contracted socket).

History of previous socket reconstruction surgery (malignant contracted socket).

History of any malignant tumour- ocular as well as systemic cause.

In cases of MMG with conformer patient having history of tobacco or betel nut chewing (submucosal fibrosis)

Clinical examination of socket was done in mainly in respect of central fornices depth was measured with the help of Castroviejo calipers pre-operatively and post-operatively. Other examination of sockets that were carried out was the area of the socket, volume of the socket, contracture and fornix shortening and presence of symblepharon to rule out severely contracted socket.

\section{Group A: AMG with conformer}

Surgical Technique: Local anesthesia was preferred for cases with mild to moderate contracture and in cooperative subjects, but general anesthesia was given in subjects with excessive scarring and in younger or uncooperative patients.

Step 1: The subconjunctival scar tissue was dissected and released from the episclera along with symblepharon release.

Step 2: Temporarily application of conformer to assess the depth of fornix is well enough to retain the conformer.

Step 3: Application and suturing of AMG. A layer of AM was applied to cover the exposed bare episclera. Epithelial side of AM was faced up. The size of the required $\mathrm{AM}$ varied from $5 \mathrm{~mm}$ to $11 \mathrm{~mm}$.

Step 4: Adequate-sized conformers were placed in all the cases to prevent post-operative scarring and fibrosis

\section{Group B: Mucous membrane graft with conformer Surgical Technique}

Step 1: Release of fibrous tissue and adhesion from the fornices

Step 2: Temporary use of conformer to assess the depth of fornices for retaining conformer.

Step 3: Obtaining mucuos membrane graft from the inner side of the lower lip. $2 \%$ xylocaine with adrenaline is injected under the mucuos membrane. An elliptical incision was given and seprated from underlying tissue (care is to be taken- incision should not to be cross the muco-cutaneous junction \& frenulum below. Suturing is not required as the vascular mucosa heals very fast. Pressure dressing may be given to stop oozing. It is better to avoid too much cautery as this can cause scarring and distortion of the lips.)

Step 4: grafting of mucous membrane into the fornices with suturing the graft with the released conjunctiva. Smooth surface of the graft should be place facing outward.

Step 5: Conformer is placed to prevent symblepharon formation.

Postoperatively, oral and topical antibiotic and oral analgesics were given to the patients for 7 days. Topical antibiotic and a lubricant was continued for another 2 weeks. Then topical antibiotic-steroid drops was also prescribed for another 2 weeks. At the end of this period, the dose of the steroid-antibiotic drops and ointment was gradually tapered over 2 months. However, lubrication was continued for 3 to 4 months. Conformers were left in place for 4-6 weeks. Regular cleaning of the conformer was instructed to the patients or their attendants. The patients were followed up regularly every week for a month to observe for any post-operative complication or graft rejection. After 4-6 weeks, when the socket bed with graft heals properly the conformer was replaced with prosthetic eye and patients were advised to have a follow-up on $3^{\text {rd }}, 6^{\text {th }}$ and $9^{\text {th }}$ post-operative month and central inferior fornix depth were measured on these visit. In the follow-up period, observations were also made for any complications such as infection, graft rejection, contractures, fornix shortening, or recurrence of symblepharon.

Complete success of the procedure was considered when there was restoration of an anatomically deep fornix with retention of the prosthesis, while partial success was defined when there was any focal recurrence of scar and symblepharon but still it was possible to retain an artificial eye. Failure was considered when there was recurrence of extensive symblepharon or shallow fornix with failure to retain the prosthesis.

\section{Observation}

Table 4: Number of patients with mild and moderate contracted socket

\begin{tabular}{|l|c|}
\hline Grade of contracted socket & No. of cases \\
\hline Grade I/ Mild & 11 \\
\hline Grade II/ Mild & 6 \\
\hline Grade III/Moderate & 3 \\
\hline Total & 20 \\
\hline
\end{tabular}


Table 5: Group A showing the grade of contracted socket with pre-operative and $9^{\text {th }}$ month post-operative central inferior fornix depth and with the outcome

\begin{tabular}{|l|c|c|c|c|c|}
\hline S. No. & Grade & $\begin{array}{c}\text { Pre-operative central } \\
\text { inferior fornices depth } \\
(\mathbf{m m})\end{array}$ & $\begin{array}{c}\text { Post-operative central } \\
\text { inferior fornices depth } \\
(\mathbf{m m})\end{array}$ & $\begin{array}{c}\text { Post-operative } \\
\text { complication }\end{array}$ & $\begin{array}{c}\text { Outcome on 9th post- } \\
\text { operative month }\end{array}$ \\
\hline 1 & III & 2.8 & 6.9 & Nil & Complete Success \\
\hline 2 & II & 3.5 & 7.1 & Nil & Complete Success \\
\hline 3 & I & 3.2 & 7.2 & Nil & Complete Success \\
\hline 4 & III & 3.1 & 7.0 & Fornix Shortening & Partial Success \\
\hline 5 & II & 3.6 & 7.1 & Nil & Complete Success \\
\hline 6 & I & 3.4 & 7.2 & Nil & Complete Success \\
\hline 7 & II & 2.8 & 6.8 & Fornix Shortening & Partial Success \\
\hline 8 & I & 3.4 & 7.2 & Nil & Complete Success \\
\hline 9 & I & 3.1 & 7.1 & Nil & Complete Success \\
\hline 10 & I & 3.0 & 7.3 & Nil & S \\
\hline & & $3.19 \pm 0.28$ & $7.09 \pm 0.15$ & & \\
\hline
\end{tabular}

Table 6: Group B showing the grade of contracted socket with pre-operative and $9^{\text {th }}$ month post-operative central inferior fornix depth and with the outcome

\begin{tabular}{|l|c|c|c|c|c|}
\hline S. No. & Grade & $\begin{array}{c}\text { Pre-operative central } \\
\text { inferior fornices } \\
\text { depth (CM) }\end{array}$ & $\begin{array}{c}\text { Post-operative central } \\
\text { inferior fornices depth } \\
\text { (CM) }\end{array}$ & $\begin{array}{c}\text { Post-operative } \\
\text { complication }\end{array}$ & $\begin{array}{c}\text { Outcome on 9th post- } \\
\text { operative month }\end{array}$ \\
\hline 1 & I & 3.4 & 7.1 & Nil & Complete Success \\
\hline 2 & I & 2.8 & 7.0 & Nil & Complete Success \\
\hline 3 & I & 3.1 & 7.2 & Nil & Complete Success \\
\hline 4 & I & 3.0 & 7.1 & Symblepharon & Partial Success \\
\hline 5 & II & 2.8 & 6.7 & Nil & Complete Success \\
\hline 6 & I & 3.3 & 7.0 & Fornix Shortening & Partial Success \\
\hline 7 & III & 2.8 & 6.8 & Fornix Shortening & Partial Success \\
\hline 8 & II & 2.9 & 6.7 & Nil & Complete Success \\
\hline 9 & I & 3.4 & 7.1 & & Nil \\
\hline 10 & II & 2.9 & 7.0 & & \\
\hline & & $3.04 \pm 0.24$ & $6.94 \pm 0.15$ & & \\
\hline
\end{tabular}

\section{Results}

20 patients of contracted socket were included in this study and randomly 10 patients each were categorized into Group A- amniotic membrane graft + conformer and Group B- mucous membrane graft + conformer.

Group A: AMG + Conformer: Mean age group- 41.6 \pm 12.93 (10-60 years). The mean pre-operative central inferior fornix measured- $3.19 \pm 0.28 \mathrm{~mm}$ and mean post-operative central inferior fornix measured $7.09 \pm$ 0.15 , paired t-test was used for statistical analysis, $\mathrm{p}$ value 0.0001 , which was statistically very significant. Complete success in retaining the prosthesis in postoperative $9^{\text {th }}$ month was achieved in 8 cases $(80 \%)$ while 2 cases $(20 \%)$ had partial success due to fornix shortening(slight difficulty in retaining the prosthesis). There were no AMG rejection.

Group B: MMG + Conformer: Mean age group- 41.9 \pm 15.84 (10-60 yrs). The mean pre-operative central inferior fornix measured- $3.04 \pm 0.24 \mathrm{~mm}$ and mean post-operative central inferior fornix measured- $6.94 \pm$ 0.18 , paired t-test was used for statistical analysis, p- value 0.0001 , which was statistically very significant. Complete success in post-operative $9^{\text {th }}$ month was achieved in 7 cases $(70 \%)$ while 3 cases $(30 \%)$ had partial success due to fornix shortening in 2 patients and mild symblepharon in 1 patient. There were no MMG rejection. 


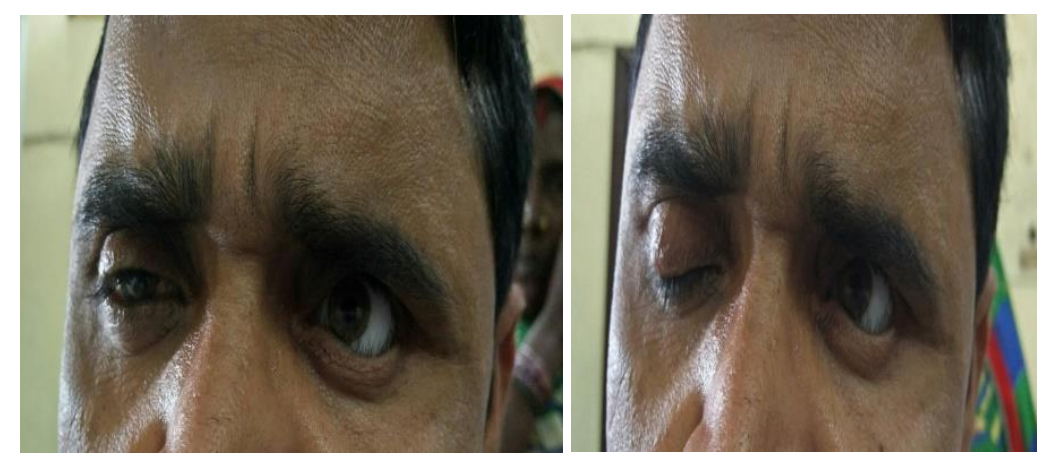

Fig. 1: Patient with an oddly fitted prosthetic eye, note the abnormal position of the both lids (A) both eyes open (B) closed eyes

\section{Discussion}

Anophthalmic socket with contraction and/or shallow fornices due to subconjunctival fibrosis or formed symblepharon was a reason- for difficulty in using ocular prosthesis which posed a major aesthetic concern for the patient. Main factors leading to socket contracture include deep scar formation from the previous injury or due to extensive dissection of conjunctiva in previous surgeries, atrophy of orbital fat, extensive loss of conjunctiva and fornix contraction. ${ }^{5}$

Successful fornix reconstruction of the contracted socket requires a well formed superior and inferior fornix with adequate depth by increasing the surface area with the use of grafts. Several graft materials such as oral mucosa, hard palate mucosa, skin and use of dermis-fat grafts have been described for socket reconstruction. A major issue comes in all the mentioned grafting procedures is the need to harvest tissue from another site of the same patient, where its availability may be limited. The harvesting of the tissue requires additional surgical skill and instrumentation as well as manipulation. Some study conducted showed that if fibrosis and contraction of the socket begins in these procedures then the patient may require multiple intervention to maintain an adequate socket for retention of the prosthetic eye. ${ }^{6,7}$

Several recent studies have described use of amniotic membrane as a substrate graft in mild contracted socket, where AM allows the conjunctival epithelium to multiply and migrate over its surface for proper prosthesis fitting. Other study by Tseng et $\mathrm{al}^{8}$ showed the intraoperative application of mitomycin $\mathrm{C}$ (MMC) during AM grafting which effective reduces the chronicity of the inflammation in the fornix after symblepharon lysis and thereby helping the amniotic graft to epithelized and migrate over the conjunctival surface to restore a deep fornix after the procedure. MMC was not used in our series because most of our cases had mild to moderate contracture and a good probability of success without adjunctive agents. Other procedures such as in cases of contracted socket with symblepharon was used of AMG with symblepharon ring had also a better outcome in these patients.
Mucous membrane grafts is also a good option in healthy patients with a healthy socket i.e socket with a good vascularity. MMG was even better option for sockets who had shallow sockets, with loss of extensive conjunctiva and orbital fat. In our study we harvested mucous membrane graft from the lower lip, thereby some candidates were excluded where the obtaining of the graft was limited (patients who presented with submucosal fibrosis or had a habit of tobacco or betel nut chewing). Lukáts ${ }^{9}$ studied on severely contracted conjunctival sacs where he used a silicone sphere as an expander for widening and deepening of the socket. In our series, conformers were used in all patients to prevent scarring and fibrosis.

In this study conducted we were able to achieved complete success in 8 eyes (80\%) out of total 10 eyes in group A and 7 eyes (70\%) out of 10 eyes in Group B. Based on our results, the limitation of using AMG as well in group A and group B showed partial success when the symblepharon covered a large surface area and required larger resectioning of fibrous tissue to deepen the inferior fornix this technique is not successful in 20\% with AMG with conformer and 30\% in MMG with conformer.

AM has become more popular because of its favorable results in fornix and socket reconstruction. This material could be an ideal graft that is readily available and in abundance, without sacrificing the patient's own tissue. AM can be easily harvested, undergoes minimal shrinkage, is resistant to contraction, and has a short healing period with no donor site morbidity. These characteristics make the $\mathrm{AM}$ a suitable graft for fornix reconstruction.

\section{Conclusion}

In summary, AMG and mucous membrane grafted from lower lip with a conformer is a simple and safe method for fornix reconstruction in mild to moderate contracted socket; it provides effective deepening of the fornix to retain the ocular prosthesis. Mucous membrane grafting was not possible in some cases where there was buccal mucosal fibrosis those patients were excluded from the study. Whereas AMG was easily available. 


\section{References}

1. Krishna G. Contracted sockets--I (aetiology and types). Indian J Ophthalmol 1980;28:117-20.

2. Korneeef L. Spatial aspects of orbital musculofibrous tissues in man. Amsterdam and Lisse, Swets and Zellinger, BV, 1977.

3. Vistnes L. The eye socket In: Repair and reconstruction in the orbital region, 3rd ed. Churchill Livingstone $1991 ; 335$.

4. Tseng SCG, Prabhasawat P, Lee S-H. Amniotic membrane transplantation for conjunctival surface reconstruction. Am J Ophthalmol. 1997;124:765-774.

5. Rahman I, Said DG, Maharajan VS, Dua HS. Amniotic membrane in ophthalmology: Indications and limitations. Eye (Lond) 2009;23:1954-1961.
6. Kumar S, Sugandhi P, Arora R, Pandey PK. Amniotic membrane transplantation versus mucous membrane grafting in anophthalmic contracted socket. Orbit. 2006;25:195-203.

7. Sangwan VS, Burman S, Tejwani S, Mahesh SP, Murthy R. Amniotic membrane transplantation: A review of current indications in the management of ophthalmic disorders. Indian J Ophthalmol. 2007;55:251-260.

8. Tseng SC, Di Pascuale MA, Liu DT, Gao YY, Baradaran-Rafii A. Intraoperative mitomycin $\mathrm{C}$ and amniotic membrane transplantation for fornix reconstruction in severe cicatricial ocular surface diseases. Ophthalmology. 2005;112:896-903.

9. Lukáts O. Contracted anophthalmic socket repair. Orbit. 2002;21:125-130. 